\title{
2 \\ Using Networks to Find Out about Networks
}

\section{The significance of personal networks in studies of the Russian economy}

The notion of network refers to a system consisting of nodes and the links between them. A social network may be distinguished from, say, computer networks by the fact that the nodes of the network are social actors. Often the nodes are individual persons, but in principle they could also be groups of people, cities, states, social organizations, and so on. ${ }^{1}$

In this book, however, a notion of personal network consisting of an individual person (ego) and the people (network members or alters) with whom s/he has relations is used. ${ }^{2}$ What constitutes a 'relation' depends on the study question. Typically, though not necessarily, a personal network may contain colleagues, family and kin, friends and acquaintances, neighbors, and so forth. ${ }^{3}$

The central idea of this book is that in the Russian context the notion of personal network is, in addition to being a researcher's tool for collecting and analyzing empirical data, also recognized by the actors themselves as a conventional means of coordinating economically relevant transactions. In more concrete terms: turning to one's personal network instead of formal economic institutions is a common way of conducting various transactions and solving problems in the Russian economy.

As will become evident later in this book, this convention of turning to one's personal network has its roots not only in the Soviet period and probably in Imperial Russia - but also in perestroika and the transition era. On the one hand, and somewhat paradoxically, the introduction of the principle of market competition to the economy forced the new Russian entrepreneurs to turn to their existing networks, but on the 
other hand, it led to conflicts and tensions between the 'network' and 'market' modes of coordinating transactions.

In studying the Russian economy, the notion of personal network has several advantages. First, in Russia the ties connecting organizations generally and firms in particular are often highly personal in nature. In other words, the interrelations between organizations are based, instead of on formal organizational roles, on the personal relations between particular individuals (Salmi and Bäckman 1999; Brygalina and Temkina 2004; Salmenniemi 2008).

Second, the notion of personal network allows for relating the life history of an individual to the interaction with his personal network members. This makes it possible to combine aspects of both agency and structure in the analysis, but more importantly, to investigate the formation of social ties, often neglected in social network research.

Third, and closely related to the previous point, the notion of personal network enables one to illustrate the mixing of 'personal' and 'professional' spheres of life in Russia. ${ }^{4}$ A network study focusing only on the ties between colleagues within one organization cannot grasp the overlap and intertwining of social ties at and outside work (Lonkila 1998, 2010).

Fourth, the notion of personal network corresponds closely with the way Russians speak about their social relations. The Russian language contains several expressions referring to personal networks, such as moi krug (my circle), okruzhenie (surrounding), blizkii krug (close circle), krug obshcheniia (circle of socializing) and krug znakomykh (circle of acquaintances). ${ }^{5}$ It is central for the purposes of this book that these expressions depict precisely personal networks anchored around focal individuals and containing different types of social relations such as family, kin, friends, and colleagues. The mixing of these relations in the personal networks of Russian IT business is one of the main findings of this study, but seems also to be a more general feature of the Russian society. ${ }^{6}$

Finally, the great amount of time and effort placed on specific social rituals related to personal networks, such as birthday parties and celebrations, is indicative of their significance. In Russia, birthdays of the members of the extended family, friends, acquaintances, and colleagues are remembered and celebrated - often on several occasions - both at home and at work to a much greater extent than, say, in the US (Visson 2003, for a closer account on birthdays see Chapter 5).

Our use of personal networks in social research owes much to the works of the Manchester school anthropologists (see, for example, 
Mitchell 1969). For them the use of the notion was a conscious theoretical and methodological choice which allowed, for example, the investigation of the multiplexity of social ties (Gribaudi 1998). ${ }^{7}$ This book follows that lead by paying particular attention to the overlapping spheres of life as detected through personal network data.

The micro-level perspective implied in the use of the notion of personal network is similarly indebted to the recent anthropological research on Russia. This research, which emphasizes the importance of studying Russian society on a grassroots level, has produced some of the most interesting views on the Russian economy and society (e.g. Burawoy and Verdery 1999a; Ashwin 1999; Humphrey 2002; Yurchak 2006). ${ }^{8}$

In all, turning to one's personal network is a conventional way to effectuate transactions and solve various problems in the Russian economy. Understanding the nature of the present-day Russian market economy requires a detailed examination of the functioning of these networks, which is the aim of the empirical analysis of this book.

\section{The qualitative approach in social network analysis}

Many of the contributions and achievements of social network analysis have come from the 'structural school' (e.g. Wellman and Berkowitz 1988), which is based on modeling and analyzing the patterns of ties between the members of networks. The critics of the structural school have claimed since the 1990s that this modeling has been carried out at the expense of reflection on the nature and content of the ties (e.g. Emirbayer and Goodwin 1994; Smith-Doerr and Powell 2005).

Stressing network structure at the expense of the nature of social ties runs the risk of universalizing the results mainly based on data collected in Western countries and consequently downplaying cross-country differences. The comparative research on friendship networks suggests, for example, that there is variation in the rights and duties related to friendship (Fischer 1982; Castrén and Lonkila 2004). From this viewpoint, the questions on friendship used in international comparative surveys take as a fixed point of departure a category which itself should be questioned and studied.

This study belongs to the strand of qualitative and mixed-methods approaches to network analysis (Lonkila 1999a; Castrén 2000; Salmi 2006; Fuhse 2009) in which, instead of network structure, the meaning and formation of personal network ties are at the center of attention. ${ }^{9}$ It responds to the call by Smith-Doerr and Powell (2005: 394) for 'more 
process-oriented, case-based approaches' which should offer accounts of 'why ties are created, how they are maintained, what resources flow across these linkages, and with what consequences' ${ }^{10}$

Because an important part of the respondents were shareholders or owners of St. Petersburg IT firms, this study also contributes to the research literature on entrepreneurship. Following Hoang and Antoncic (2003), this research addresses three essential components of social networks: the content, governance, and structure of the relationships. As for the content of the networks, network ties are considered to be the media through which actors gain access to resources held by other actors. The governance refers to mechanisms that coordinate network exchanges, and the structure denotes the pattern of relationships between actors (Hoang and Antoncic 2003: 166).

In this book, emphasis is laid on the role of personal networks in the transmission of resources. In the classification by Hoang and Antoncic, the focus is thus on the content of the ties (dealt with in Chapter 6), as well as on the mechanisms governing the functioning of the network (dealt with in Chapter 7). The modeling of network structure, which is primary in the structural network analysis tradition, will receive less attention and is included in the analysis mainly while discussing the role of brokerage (Chapter 7).

From the viewpoint of resource transmission, this study thus started as a 'connectionist' variant of social network analysis (Borgatti and Foster 2003: 1002) focusing on the resources that flow through social ties:

Ties are seen, often quite explicitly, as conduits through which information and aid flow (...) In this conception, an actor is successful because she can draw on the resources controlled by her alters, including information, money, power, and material aid. This perspective is also implicit in the social support literature (...) and in most network research on entrepreneurs.

(Borgatti and Foster 2003: 1002)

However, during the study it became evident that the transmission of economically relevant resources in the networks could not be separated from social, cultural, and moral issues. Both the qualitative and quantitative data suggest that the mechanisms governing the network exchanges were not only based on atomistic individuals' rational calculations, but were also deeply affected by social and moral considerations. 


\section{Network data and how to get them}

This book is based on the analysis of semi-structured interviews and personal network data collected among St. Petersburg IT professionals during 2003-6 (interviews) and in 2004 (network data).

\section{The qualitative interview data}

The interview data consist of semi-structured interviews conducted in St. Petersburg from 2003 to 2006 with 50 top- and mid-level IT directors and managers. ${ }^{11}$ Of the 50 respondents, 38 were under 40 years of age and eight were women. ${ }^{12}$ Except for two respondents, all had a university degree, and several had either a licentiate ${ }^{13}$ or doctoral degree. The majority of the companies where respondents worked were owned by Russians, but the data also include foreign-owned companies and joint ventures. The bulk of the firms were established in the 1990s. ${ }^{14}$

Independently of this study, Melanie Feakins (2007) conducted interviews among St. Petersburg software companies involved in offshore programming. Feakins' vivid characterization of her respondents applies mutatis mutandis to ours - more so since some of our interviewees were probably overlapping:

A large proportion of the firms interviewed were established by entrepreneurs with PhDs who had left teaching, research, and academic life to establish firms with colleagues, friends, spouses, and as individuals. (...) Many were hesitant, amused, pleased, and sometimes still shocked that they have become entrepreneurs in the post-Soviet world, particularly because it had not been imaginable in the Soviet Union. (...) As a category of people, their deliberate distance from state administration and enterprise life of the Soviet period separates them distinctly from apparatchiks and new elites whose positions and wealth in post-Soviet society are derived largely from conversions of their political status to material wealth and/or participation in privatization schemes of enterprises and natural resources.

(Feakins 2007: 1892)

In line with Feakins' account, one of our respondents, a middle-aged Russian firm owner, described his situation upon the demise of the Soviet system as an unemployed engineer 'who was of no use to anyone'. Starting from nothing, he had built a flourishing software company that employed a considerable number of people and was growing yearly. Despite this success, he lived, behaved, and dressed modestly 
and, instead of using the profits to improve his lifestyle, he invested most of his money in the development of the firm. ${ }^{15}$

Finding respondents was tricky. As IT professionals are generally busy people, finding time for one to two hour interviews from the daily chores of Russian business required a remarkable amount of work and preparation from our native Russian research assistant. Luckily, the process of locating and persuading potential candidates to be interviewed turned out to be part of the phenomenon we studied in several ways.

First, the respondents were often found through the interviewer's personal networks, and sometimes through the network of the author of this book. This process illustrated the importance of personal ties and brokerage in making things happen in Russia, as becomes evident from the field notes of the research assistant:

Respondent [project leader, p23] was found thanks to Vadim Grigor'evich [a friend of the author] (...) Generally, the interview went very sympathetically but this was basically due to Vadim Grigor'evich's mediation. After the interview the respondent confessed that without this mediation he would not have agreed to be interviewed.

Another reluctant respondent (system administrator, p32) finally agreed to be interviewed, probably influenced by the fact that he had been the classmate of the son of our interviewer's acquaintance, who, in his turn, was acquainted with the interviewer's mother.

Second, the respondents often seemed to agree to be interviewed thanks to the particular role of the 'ethics of helping out' in Russian culture which will be analyzed in detail in Chapter 7 of this book.

Third, our research assistant's field notes about the atmosphere and communication prior to, during, and after the interview illuminated the mixing of professional and personal spheres of life, one of the main themes of this book, in the interaction between the Russian interviewer and the Russian respondents. On several occasions the interview started out in a professional tone and floated to the areas of common interests and personal life of both parties.

All these aspects will be discussed in detail in later chapters. Here it suffices to say that the very process of data collection already illustrated the main substantial results and theoretical ideas of this book, justifying its detailed examination here as much as a result of the study as a description of its methods. 
As a rule, interviews were conducted in a relaxed atmosphere either at the office, café, car, or even home, often accompanied by a cup of coffee or tea. The main disrupting factors were work-related time pressures and occasional interruptions by workmates. Out of 50 interviews, only one turned out to be a truly unpleasant experience:

I would not want to meet this person another time. He demonstrated benevolence, willingness to help. But his whole tone of speaking, expressions and questions could be experienced as an attempt to show who is who here. I felt like I was interrogated. The only reason I let the respondent treat me this way was that this was for him the most natural way of interacting with people whom he considered inferior to him. Prior to the interview the respondent asked questions about my university and faculty and my understanding of sociology. Then he said that I have exactly one hour for the interview, and put the clock on the table in front of him. When he saw my list of questions, he grabbed it and started reading and answering the questions himself. In the course of the interview I asked complementary questions. When the interview had ended, the respondent boasted about that we managed to finish in one hour.

(interviewer's field notes)

During his reading and answering the questions, the respondent mentioned that his firm was working for 'state structures' (gosstruktury) and replied 'confidential', for example, for questions about the number of employees and the location of offices.

Fortunately, this kind of reception was an exception. Generally, our respondents related to the study positively and seriously, trying to explicate the details of their business practices and use of social ties to the best of their understanding. ${ }^{16}$

Though interviews were conducted by a native Russian and the respondents were guaranteed anonymity, it would be naïve to assume that the respondents would have openly shared all aspects of their business activities. Some refused to answer certain questions referring to business secrecy while others expressed right away that they wouldn't reveal all they knew about the topic at hand:

I won't tell everything about this case. There are simply things I won't tell even if protected by anonymity. Believe me, there are situations where not even close to everything can be written into a 
contract. And in this case the guarantee for everything being done right and on time is the word of the person you are dealing with.

(general director, $\mathrm{p} 4$ )

Therefore, one most likely 'underrepresented' theme of the study is the corrupt and informal practices of Russian business (cf. Chapter 4 of this book). Because of the wealth of studies on this topic and the focus of this study on the 'routinized' and legal ways of acting through networks, this is not a serious shortcoming.

\section{Personal network data}

Data on personal networks were collected in spring 2004 through a web-based network questionnaire. ${ }^{17}$ Respondents were selected from the catalogue 'The whole computer world, St. Petersburg 2003' (Ves' kompyuterny mir, St. Petersburg 2003), which contained data on 1048 firms in the field, and through the research group's own connections. Though the catalogue hardly included all firms active in St. Petersburg at the time, it contained a wide variety of entrepreneurs dealing with software development, hardware, system integration, consulting, service providing, and so forth. (The firms dealing only with computer hardware trade were not included in the survey.)

Selected firms were first approached by phone to find the e-mail address of a person who could and would answer our questionnaire. This person was then sent the weblink of our survey by e-mail. In the survey the respondents were asked to describe a successful project or work task which they had completed in 2003, and to name the three most important people (that is, their personal network members or 'alters') involved in the implementation of the project.

In addition, they were asked to name two more people who had been important for their whole career in ICT. Lastly, the respondents were asked to name one person who lived abroad and had had the most important effect on their whole activity in ICT (for more details, see Lonkila 2006). After having generated the list of names of their network members, the respondents indicated in a network matrix if, to their knowledge, their network members knew each other - that is, had been in mutual contact. In addition, the questionnaire contained free-form fields where the respondents could characterize their network members in their own words. This qualitative data turned out to be very interesting for the purposes of this book. ${ }^{18}$

The complete web survey network data corpus contains information on 72 respondents and 343 network members. The respondents were 
67 young or middle-aged male and five female ICT professionals from St. Petersburg, almost half of them younger than 36 years. Seventy percent of them had an MA degree, 22 percent were licentiates or doctors, and they were working in mostly small- or medium-sized ICT companies. The respondents were well placed in their own organizations: 28 percent were CEOs, 39 percent top directors, and 29 percent managers. In addition, 43 percent were shareowners in their companies. The 343 network members were also mostly young and middle-aged men, the majority of them working either as CEOs (18 percent), directors (20 percent), or managers (20 percent).

The web survey data cannot be considered representative. Neither can we calculate the response rate since the information of our study was also diffused through our own connections who informed their acquaintances and friends of our survey. Nevertheless, combined with the interview data, it gives a vivid picture of the meaning and functions of personal networks in the most modern part of the Russian economy.

\section{Limitations of the study}

This book focuses primarily on factors facilitating the transmission of resources and connecting actors. Network ties can, however, also be used strategically to exclude others, and their use may also have negative consequences both on micro and macro levels (e.g. Ledeneva 2004: 8-9). Ronald Burt's influential theory of structural holes, for example, is based on the tertius gaudens (the third who gains) idea borrowed from Georg Simmel. In this perspective, network member A takes advantage of the fact that he is connected to both $\mathrm{B}$ and $\mathrm{C}$, who do not know each other. This intermediary position allows A the possibility to use it to his own advantage. However, this study follows David Obstfeld's (2005) lead instead. Obstfeld has in his study of brokerage employed the tertius iungens (the third who joins) perspective, that is, the active role of network members in creating the connections between other network members (see Chapter 7).

Second, this book does not use the concept of social capital. Without denying the achievements of the large research literature on social capital, the notion is problematic for the tasks of this study. In her review on the problems of the notion, Salmi (2006: 51) notes how the leading theorists (Pierre Bourdieu, James Coleman, and Robert Putnam) all stress different aspects of the concept. More importantly, the very essence of the notion remains vague. In the well-known formulation of 
Robert Putnam (1993: 167), for example, social capital consists of trust, norms, and networks, each of which remains vaguely defined.

One problem pointed out by critics is that social capital is often used in a very unfocused manner. Social capital means different things depending on the tradition one draws from and, in the worst case, can mean just about everything, as has been argued by Portes. He claims that Coleman started the proliferation of the concept by including 'a number of different and even contradictory processes' in the term, some of which are the mechanisms that generate social capital and some the consequences of its possession (Portes 1998, 5).

(Salmi 2006: 51)

Third, this book focuses on the role of social ties between human beings involved in economically relevant transactions. Formalized solutions such as standards and certifications are certainly of importance, but the emphasis of this study is rather on the ways of circumventing these standardized solutions with the use of social ties.

\section{Problems of generalization}

The structure, composition, and functioning of the personal networks is influenced by several factors which have to do with the properties of the respondents (age, sex, place of birth, life course), their position in the organization (programmer vs. manager), and the characteristics of the company (field of industry, size, age, and so forth). For example, the role and meaning of networks is likely to change during the life cycle of a company. When acquiring customers, a small, start-up firm may be more inclined to use personal relations than a bigger company that has already established a stable client base. ${ }^{19}$ On the other hand, as will become evident later, even big companies are sometimes forced to turn to their networks, in order to win tenders, for example.

Many respondents also noted that networks function differently in offshore IT companies oriented toward foreign customers and adapted to Western standards of conducting business on the one hand, and in companies operating in domestic markets alongside big state-owned companies on the other hand. Because of the qualitative nature of this study, all of these 'background variables' cannot, however, be systematically investigated.

Finally, the gender aspect merits both methodological and substantial comment. From the methodological viewpoint one has to note that 
the interview situation consisted of a young Russian female student conducting interviews mostly with middle-aged Russian men. Because of the Russian gender system, this age and gender difference probably helped in obtaining interviews from the busy IT directors and managers. Moreover, in the interview situation some of the interviewees took a 'teaching position', which was often helpful in terms of creating an overall picture of the field. Most important, however, is to acknowledge that the gender difference most likely emphasized some aspects of the phenomenon studied and concealed others.

Substantially, both Russian business and the IT field are maledominated areas of life. This provoked a lively discussion between one of our female respondents (team leader, p37) and the female interviewer about the role of women in the IT business. The respondent noted that women are treated differently, and those starting from the bottom in the IT business have a harder time than men. This difference is, however, of complex character and contains several contradictory elements. According to her, being a woman has negative consequences until one has gathered enough experience, when the gender factor 'starts to function strongly in your favor.' Moreover, there are both places 'where they don't take you because you are a woman' and places 'where they will take you exactly because you are a woman.' The respondent also related the gender aspect to the nature of the male Russian 'work collective' in IT business:

Firstly, many [Russian IT professionals] think that women cannot work as programmers. Secondly, many think that it is a crazy idea to take a woman into a company consisting of 20 men, because this spoils the collective and the mood of the men. And then one has to remember that women have a tendency of taking maternity leave. In the firm I worked at earlier, practically all of the women took maternity leave. Well, not all, but those with whom I myself had come to the company.

(team leader, p37)

Another female respondent belonging to top management stated that programming and engineering professions 'are not women's affairs' (ne zhenskoe eto delo) - unlike marketing, where women can use 'fine tools' (tonkimi instrumentami mozhno vladet') (director, p41). Still another female respondent (PR manager, p2) considered how 'for women the family will always be first'.

These replies illustrate aspects of the Russian gender system that cannot be dealt with in detail here (for an account of entrepreneurship 
in gender terms, see Shmulyar Gréen 2009: 93-8). However, considering the examples given above, it is likely that a systematic analysis of the women managers' networks would confirm rather than refute the tendency toward mixing of personal and professional spheres of life observed in this study.

In sum, this book describes mostly owners', directors', and managers' use of networks in small- and medium-sized Russian software companies, though it also includes interviews with employees from some of the biggest software companies in St. Petersburg. For the purposes of this book this bias toward SMEs (small- and medium-sized enterprises) firms is not fatal. First, the flourishing SMEs are considered important to the dynamics of the market economy, and even the biggest companies have started small. Second, the larger and more important the company is, the more it runs the risk of getting involved in deals with state-owned companies or involved in the top-level politico-economic struggles. Thus, for a study of the emerging Russian market economy, SME companies are a good starting point. 